\title{
Reply to the letter to the editor by Satvinder Singh Bakshi concerning: 'Is neutrophil-lymphocyte ratio associated with the severity of allergic rhinitis in children?'
}

\author{
Mahmut Dogru ${ }^{1} \cdot$ Muhammed Fatih Evcimik $^{2} \cdot$ Ahmet Adnan Cirik $^{3}$
}

Received: 22 July 2016/Accepted: 25 July 2016/Published online: 29 July 2016

(c) Springer-Verlag Berlin Heidelberg 2016

To the Editor,

We would like to thank the author of the letter for contributing valuable comments to our article entitled "Is neutrophil-lymphocyte ratio associated with the severity of allergic rhinitis in children?" [1]. However, we think that the author has missed some points. First, all patients with any chronic disease were not enrolled in the trial as specified in the materials-method section of the article. This includes patients with Bell's palsy, chronic tonsillitis and hearing loss. Second, regarding the relationship between the age, body mass index (BMI) and neutrophil-lymphocyte ratio (NLR), our trial was written in February 2015, submitted to the journal on June 28, 2015 and accepted on October 24. The publication date of the reference source is November 2015 [2]. Moreover, there were no differences in terms of age between groups in our trial. There is no consensus about NLR and BMI relationship within the literature. There are also publications in which no relationship has been detected between BMI and NLR [3, 4].

This reply refers to the article available at doi:10.1007/s00405-016-3923-7.

Mahmut Dogru

mdmahmut@yahoo.com

1 Department of Pediatrics, Zeynep Kamil Women's and Children's Diseases Training and Research Hospital, Burhanettin Ustunel Cad. No. 10 Uskudar, 38000 Istanbul, Turkey

2 Department of Otorhinolaryngology- Head and Neck Surgery, Faculty of Medicine, Istanbul Medipol University, Istanbul, Turkey

3 Department of Otolaryngology- Head and Neck Surgery, Umraniye Education and Research Hospital, Istanbul, Turkey
As we specified in our trial, our aim is to determine the relationship between the clinical parameters of allergic rhinitis and NLR in children. We did not mean to evaluate the effect on NLR of treatment or management of allergic rhinitis.

Our trial is the first trial performed in this field. We have commented on our own data. More comprehensive trials to be performed afterward would help us to draw more precise conclusions.

\section{Compliance with ethical standards}

Conflict of interest The authors declare that they have no conflict of interest.

\section{References}

1. Dogru M, Evcimik MF, Cirik AA (2015) Is neutrophil-lymphocyte ratio associated with the severity of allergic rhinitis in children? Eur Arch Otorhinolaryngol. doi:10.1007/s00405-0153819-y

2. Li J, Chen Q, Luo X, Hong J, Pan K, Lin X, Liu X, Zhou L, Wang H, Xu Y, Li H, Duan C (2015) Neutrophil-to-lymphocyte ratio positively correlates to age in healthy population. J Clin Lab Anal 29:437-443. doi:10.1002/jcla.21791

3. Nascimento H, Rocha S, Rego C, Mansilha HF, Quintanilha A, Santos-Silva A, Belo L (2010) Leukocyte count versus C-reactive protein levels in obese portuguese patients aged 6-12 years old. Open Biochem J 4:72-76. doi:10.2174/1874091X01004010072

4. Furuncuoğlu Y, Tulgar S, Dogan AN, Cakar S, Tulgar YK, Cakiroglu B (2016) How obesity affects the neutrophil/lymphocyte and platelet/lymphocyte ratio, systemic immune-inflammatory index and platelet indices: a retrospective study. Eur Rev Med Pharmacol Sci 20(7):1300-1306 